\title{
Early Manifestation of Historical Thinking in Primary School Pupils and its Diagnostics
}

\author{
Khodjaev B. Kh.
}

\begin{abstract}
:
This article outlines the early manifestation of historical thinking in primary school pupils and its diagnosis. Historical thinking is a concept that expresses the essence of man and his world as a historical being. Development of pupils' historical thinking is determined by an integrated characteristics of interconnected historical consciousness, historical knowledge, historical memory and historical worldview. In the development of pupils' historical thinking, the main didactic parameter is paying particular attention to strengthening cooperation between the "teacher - pupil”, "pupil - pupil”, "pupil - historical object”, as well as integration of possibilities of courses like "Reading", "The $A B C$ of Ethics" and additional courses like "The ABC of History" and "Journey to the World of History". It is advisable to organize pupils' independent learning activities as the main criterion for developing primary school pupils' historical thinking, assessing its results, identifying possible difficulties and ways to eliminate them, developing the ability to realize the sphere of their interests and associating them with achievements in learning activities and personal qualities.
\end{abstract}

Keywords: history, thinking, historical thinking, technology, pupil.

\section{INTRODUCTION}

The widespread use of pedagogical innovations in the educational process is considered to be a global trend of world development. Currently, the most significant was the creation of an interactive educational space, improvement of innovative methods and technologies for the development of pupils' thinking and worldview.

After independence, Uzbekistan began to pay special attention to the creation of a new democratic educational concept. "Education attaches creativity to the spirituality of the people of Uzbekistan. It reveals all the best opportunities of the younger generation, continuously improves the professional skills, and the wise experience of older generations is comprehended and transmitted to the younger ones. Young people with talents and thirst for knowledge this is where education and comprehension of spirituality begin" [Karimov I.A., 1992] - we came to this firm conclusion from this position.

Consistently developing these ideas, we started establishing a completely new system of education and training personnel as an important factor ensuring the great future of our independent country. On the basis of the Law of the Republic of Uzbekistan "On Education" and the National Program for Personnel Training, special attention was paid to the tasks of focusing education on the pupil's personality, self-awareness, comprehending the rich historical heritage, and mobilizing all the forces and opportunities to flourish the independent country.

To solve these problems, the system and content of general secondary education have been updated, that is, optimized State Education Standards and curricula for all subjects taught in Grades 1-9 have been developed and put into practice. In order to increase the efficiency of the use of advanced pedagogical and information technologies, modern teaching and methodological sets have been created.

During this turbulent time when global problems with a serious impact on the history and fate of humanity are deepening, developing the historical thinking in young learners based on the "Uzbek Model" of national independence and development are also determined by very important ideas, which were emphasized by the first President of Uzbekistan: "If today I'm asked about what needs to be done to preserve spirituality and how to fight against an attack that threatens it, then I would note, first of all, that every person living in this homeland needs to realize own personality, ancient history and rich culture through in-depth study of the heritage of great ancestors, consciously looking at the rapidly changing reality of life today, living with a sense of belonging to all the changes taking place in our country" [Karimov, 2008].

Developing electronic software for establishing in children the culture of information use and more effective educational technologies, as well as pupils' deep and full comprehension of the national historical heritage are of great scientific and practical importance in the development of historical thinking in general secondary school pupils by means of modernized didactic support as an important factor in ensuring continuity, as well as interdisciplinary relations, introduction of a competency-based approach to this process, protection from information attack, which has a negative impact on pupils' historical thinking and worldview in the context of globalization.

The development of historical thinking in pupils is mainly associated with the imagination of historical reality and awareness of its essence. The success of this process in primary education is reflected in the formation of pupils' knowledge of the material and spiritual heritage, national and universal values, historical figures, as well as the development of their valuable ideas. In the early school years, the development of historical thinking is based on the interconnectedness and unity of historical concepts with the formation of historical imagination.

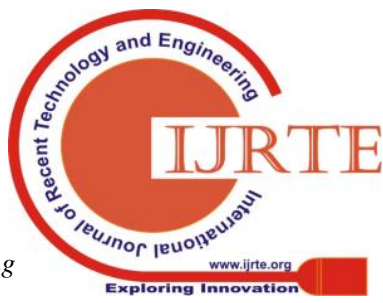




\section{METHODOLOGY AND THEORETICAL PART}

It is known that the appearance of every nation or nationality, despite it being large or small, is, firstly, clearly expressed in its national consciousness and psychology. National consciousness is the main form of ethnic consciousness, which is an integral part of public consciousness. At the same time, it is necessary to keep in mind that "Public consciousness is an objective world and a reflection of social being in the minds of people" [Rakhmonov R., Fayziev F., 2009]. Thus, every nationality and nation has an ethnic consciousness that reflects its social life. An integral part of the aforementioned ethnic consciousness is the consciousness of the clan, tribe, nationality and nation.

The study of the gradual development of historical consciousness shows that the roots of such views rest on the distant past. Especially, as Farabi wrote, "The ideas of every nation or population of a city about phenomena and events are familiar to them by the very ideas. Even in the most widespread ideas, different peoples have different ideas about the concrete creation of the world. Because each nation perceives this or that phenomenon - an event in its own way, and in its own way reflects them in its consciousness" [Farabi; 1993]. In this thought, it is shown separately as a necessary condition that each nation's historical memory should have peculiar features inherent only to it, and also that they should be associated with well-known human values.

In solving theoretical and methodological questions related to the national historical memory, the views of Biruni also have important meanings. The scientist dwelling on some negative situations in the development of national historical memory said in the language of modern terminology, i.e. ethnocentrism, that "This is stupidity, an incurable disease, it is such that, according to their conviction, there are no other lands in the world except their lands, there are no other people except their people, ... except their knowledge and sciences there are no other knowledge and sciences, and there are no other religions except their religion" [Biruni, 1991]. From these words of the scientist we may understand how sharp is his critical attitude to the situations of humiliating other nations putting own nation over others', etc.

According to Alisher Navoi, people's good knowledge of their history lays the foundation of a nation's historical thinking. Through the knowledge of the past "we can understand how a country flourished and how the people ruined themselves. Making correct conclusions from historical experience, it is necessary to take positive examples and use them with advantages" [Alisher Navoi, 2010].

Historical thinking, being an important factor in the progress of civil society, awareness of the past, and a way for its correct understanding, makes serious changes to the constituent parts of the minds and souls of pupils, through which spiritual reform can be achieved in the lives and lifestyles of citizens.

Historical thinking forms the basis of the "Uzbek Model" of national independence and progress. The pupil's mastering the whole historical world and its realities by summarizing their joint relations, understanding the basic essence of historical processes are the ability to draw reasonable conclusions from the lessons of history.

Historical thinking is a concept that expresses the essence of a person, and his world as a historical being.
Indeed, a person as an historical being, and by his social nature is not only an objective reality, at the same time, he, through very large spiritual and moral dimensions, is also a value responsible for the future, for historical duration and for the historical heredity. Only through historical thinking a person fulfils the task of the successor, the link, the bridge between the past and the future. This social reality shows itself as a phenomenon directly related to the progress of human society. Having a complex structure, historical thinking demonstrates itself connected with each other and having a mutual relationship of constituent parts: historical consciousness, historical knowledge, historical memory and historical worldview.

\section{ThEORETICAL BACKGROUND}

Historical consciousness, being one of the most important forms of social consciousness, manifests itself as a result of the process of human awareness. Various descriptions are given to historical consciousness: historical consciousness is the realization that everything was and had passed, i.e. as it happens in every science, all subjects and even the spiritual world were, but now they are not. (Philosophy: encyclopaedic dictionary) [Nazarov K., 2004]; historical consciousness is the historical events that occurred in the past and were reflected in various sources and objects passing as a heritage from generation to generation, and ensures the continuity of our history and culture [Tulenov J., 2000]; historical consciousness is also an assessment of the past, taking into account all the diversity inherent in society in general, especially various socio-demographic, socio-professional, ethno-social, ethnic and religious groups, as well as individuals. Historical consciousness is a collection of concepts about the past of society, its social groups and individuals, as well as of all humanity. In historical consciousness, the past, present and future are reflected in harmony [Rakhmonov R., Fayziev F., 2009].

In the historical consciousness there is an internal opposite, which consists of "yesterday-today-tomorrow". Acknowledging this peculiarity, A.Kh.Samiev expresses the following thought: "Historical consciousness is the assimilation by a person (social group, society) of his place in time, connections and relations of the past with the present and the future. This is very important for the future appeal to the past" [Samiev A., 1994].

Thus, historical consciousness is considered a reflection of pupil's understanding of the place of a particular individual in time, social and ethnic groups, as well as relationship between past, present and future. Historical consciousness appears on the basis of ideas and historical evidence plays an important role in this process. The category of historical evidence is considered an important measure, a scientific measurement, for researchers of the subject of history. Indeed, without evidence, ideas about history are abstract and vague, and thoughts are not argued.

Historical memory arises as a result of historical awareness and is a kind of coding of historical reality in the mind of a pupil and its repeated manifestation. According to the philosopher A.Mavrulov, knowledge of history, along with its bright and joyful days, and knowledge of periods of oppression, humiliation and colonial dependence, loss and

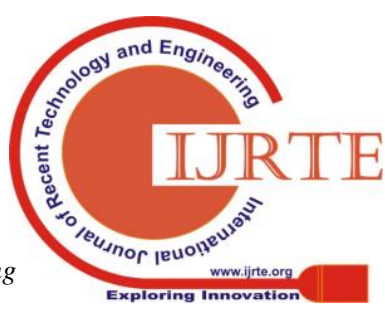


separation protects us from various disasters and adversity, and calls us to vigilance. It is not enough just to remember and be proud of achieved successes and joyful days. At the same time, for historical memory, it is extremely necessary not to forget about the dark, hopeless days of our history [Mavroulov A., 2008].

A generalized view of historical consciousness and historical memory manifests in the form of historical knowledge. According to N.Juraev, who completed a fundamental research related to historical philosophy, understanding of history begins with an interest in the sources of historical knowledge and its study [Juraev N., 2008].

When we say "historical knowledge", it is understood as a system of impressions, ideas and concepts related to the past of mankind. Historical significance, by its nature being associated with the most ancient, first appearance of man, formation of human society and emergence of methods of managing these groups, tribes and collectives, requires the study of this still ongoing huge pedigree branch of humanity. With the development of pupils' historical thinking associated with the assimilation of historical knowledge, the need for this is manifested in the following aspects:

Through the line-up of historical consciousness, historical memory and historical knowledge into a united whole, a pupil's historical outlook is formed. In turn, the historical outlook forms in the pupil the opportunity to think historically in a wide scope.

The historical outlook is a system of views related to the human past and arising in the process of its study. The historical outlook arises through social thought based on the idea of the stages of social life and historical progress of society.

\section{IMPLEMENTATION (PRACTICAL PART)}

During the formative experimental experience, pedagogical prerequisites were developed for teaching the subjects of "Reading" and "The ABC of Ethics", as well as conducting additional courses like "The ABC of History" and "Journey into the World of History" in primary classes (Figure

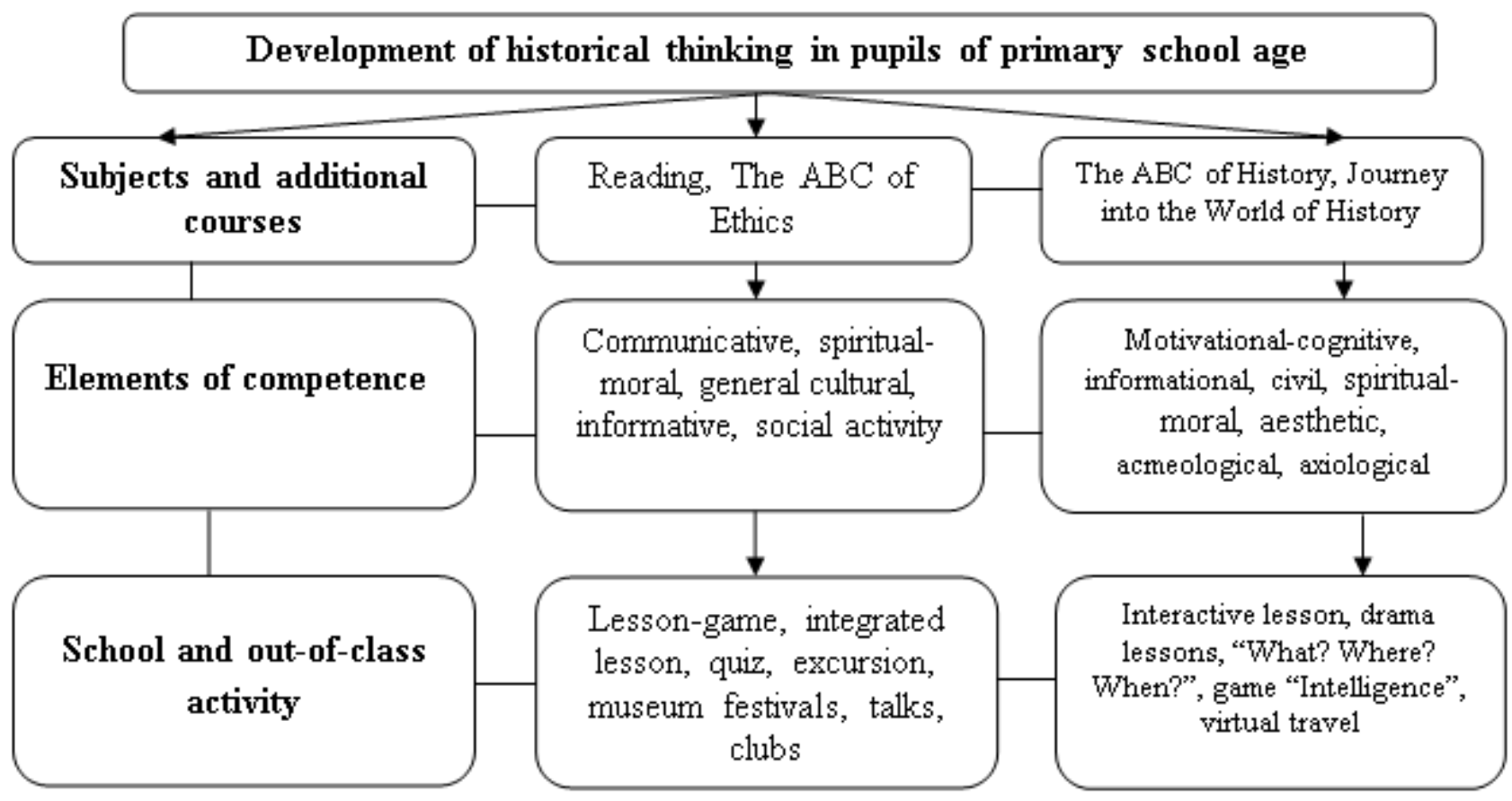

Figure 1. Pedagogical prerequisites for the development of historical thinking in primary school pupils

In the experimental schools, lessons on the subject "The ABC of Ethics" were organized on the basis of the program approved by the Republican Education Centre. The additional courses "The ABC of History" and "Journey to the World of History" were held on the basis of authors' programs and taking into account the conditions in general education schools: in Class 1 - "The ABC of History", in Classes 2-3-4 - the course "Journey to the World of History".

In the process of teaching the subjects "Reading", "The ABC of Ethics" and the additional courses "The ABC of History" and "Journey to the World of History", didactic parameters and practical-technological aspects of the development of historical thinking were effectively used, which were developed within the framework of the experiment. Along with this, based on the characteristics of

primary education, a pedagogical system has been worked out that provides mutual enrichment and interaction aimed at forming a historical view and consciousness in pupils of primary school age. This pedagogical system includes the establishment of activities aimed at forming the historical view and consciousness, clarification of its tasks, as well as the methods used in each stage of the lesson.

On the basis of the pedagogical system for the formation of historical views and consciousness in primary school pupils, an algorithm has been developed for teachers to present and pupils to learn the historical reality in tune with time and place. 
After the diagnostic system of the pedagogical experiment was worked out for the formation of historical views and consciousness in primary school pupils, primary school teachers' practical activities were started in conjunction with teachers of the subject of "History" and disciplines included in the series of "The Idea of National Independence and the Basics of Spirituality". In experimental schools, lessons on the additional course "Journey to the World of History" were conducted by leading experts.

\section{ANALYSIS AND EVALUATION OF DEVELOPMENT.}

Experimental work on the formation of ideas and consciousness as a level of early manifestation of historical thinking of pupils of primary school age was carried out in two stages:

In the first - substantiating stage, the manifestation of historical views and consciousness of primary school leavers were studied on the basis of the criteria revealed within the framework of the study. 811 primary school pupils from secondary schools No.266, No.277 and No.300 of Sergeli district of Tashkent city, No.34 of Yukori-Chirchik district of Tashkent region, No.14 of Kumkurgan district and No.13 of Termez city of Surkhandarya region, No.3 and No.100 of Shakhrisabz district of Kashkadarya region. In order to perform this work and consider the likely difficulties in its implementation, a survey was conducted among 85 teachers in primary school subjects ("Reading" and "The ABC of Ethics"), in which mainly historical views and consciousness are laid. Also, experienced primary school teachers' educational and extracurricular activities in the formation and development of pupils' historical views and consciousness were observed.

Evaluation of the effectiveness of development of historical thinking in primary school pupils was based on the following criteria: I. Motivational and cognitive: interest and need for knowledge of historical events; mastering historical concepts and terms; awareness of the content of historical events; comprehension of historical reality; II. Creative: a creative approach to historical reality; logical and analytical thinking; independent analysis of the basis of events; own views on events; III. Activity-based: demonstration of historical events in oral, written and practical forms; making independent decisions; taking others' opinions into account; substantiating own opinion and introducing changes to its essence.

\section{Discussions}

In the substantiating stage, a survey and a creative test were conducted among primary school pupils. In the organization of standard mandatory tests and revision lessons, primary school teachers regularly used tests with open answers. But since the development of historical thinking requires pupils' logical and analytical thinking and their independent decisions, the teachers used creative tests. Based on the results of the substantiating experimental work, the following conclusions were made: there are differences in the levels of formation of historical views and consciousness of primary school pupils. Only $71 \%$ of the pupils correctly completed assignments on knowledge of historical facts, $64 \%$ - of historical views of a certain period; $43 \%$ of the pupils coped with the tasks on the historical views related to creative thinking; it is necessary to organize targeted advanced training courses for primary school teachers in the subjects of "History" and disciplines that are included in the series of "The Idea of National Independence and the Basics of Spirituality". Because some primary school teachers have not fully mastered the theoretical, practical and technological aspects of the formation of pupils' historical thinking. Similarly, in primary classes of secondary schools, it is necessary to organize the work on teaching the courses "The ABC of History" and "Journey to the World of History" within the framework of optional hours; the application of innovative education strategies in practice is also of great importance in the development of primary school pupils' historical thinking.

After the subject "The ABC of Ethics" and the additional courses "The ABC of History" and "Journey to the World of History" were conducted through modernized didactic support, facilitative educational strategies were used to diagnose the knowledge and skills of primary school pupils. Prior to the beginning of the test, the pupils of the control and experimental classes were given information on the used facilitative educational strategies, and the order of implementation was shown.

The tasks carried out on the basis of facilitative educational strategies have been tested according to the following criteria: I. The period associated with the happening of a historical event: the time of a historical event, time units of measurement (century, year, month); comprehension of knowledge about the sequence and duration of historical events, the rationale for the time of the event; comparison of historical events of the world and the Motherland from a temporal point of view; evaluation of reality from the point of view of the historical epoch. II. The place associated with the happening of a historical event: knowledge of the names of places where historical events took place and how they are now called; understanding the causes of historical events of the area; evaluation of events in terms of interconnectedness with the history of our country. III. The facts related to historical events: explanation of the causes of a historical event; awareness of participants in the event; evaluation of the significance of the event.

Based on these criteria, the definition of the development of pupils' historical thinking was analysed by the following parameters: high - pupils have solid knowledge about the sequence and duration of historical events, justifying the time of the event; they can compare the historical events of the world and the Motherland from a temporal point of view; they have solid knowledge of the names of places where historical events occurred, they know the causes of historical events of the area; they can assess events in terms of interconnectedness with the history of our country; they are fully familiar with the causes of the historical event and its participants, they can fully assess the importance of the event; medium - pupils have knowledge of the sequence and duration of historical events, justifying the time of the event; they can compare the historical events of the world and the Motherland from a temporal point of view; they own knowledge of the names of places where historical events occurred, know the causes of historical events of the area; they can assess events in terms of interconnectedness with the history of our country; they are familiar with the causes of the

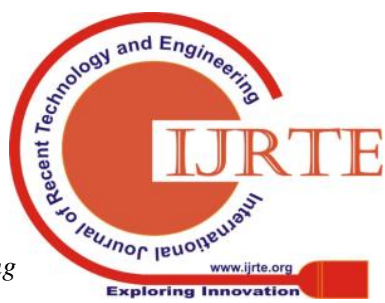


historical event and its participants; they can assess the importance of the event; low - pupils are aware of the time of happening of historical events; they know the name of the place where the historical event occurred; they have information about the participants of the event, but feel difficulty in explaining the reasons and significance of the historical event.

On the basis of these criteria and parameters, the results of tasks performed by pupils on facilitative educational strategies were analysed (Table 1).

Table 1: The results of tasks performed by primary school pupils on facilitative educational strategies

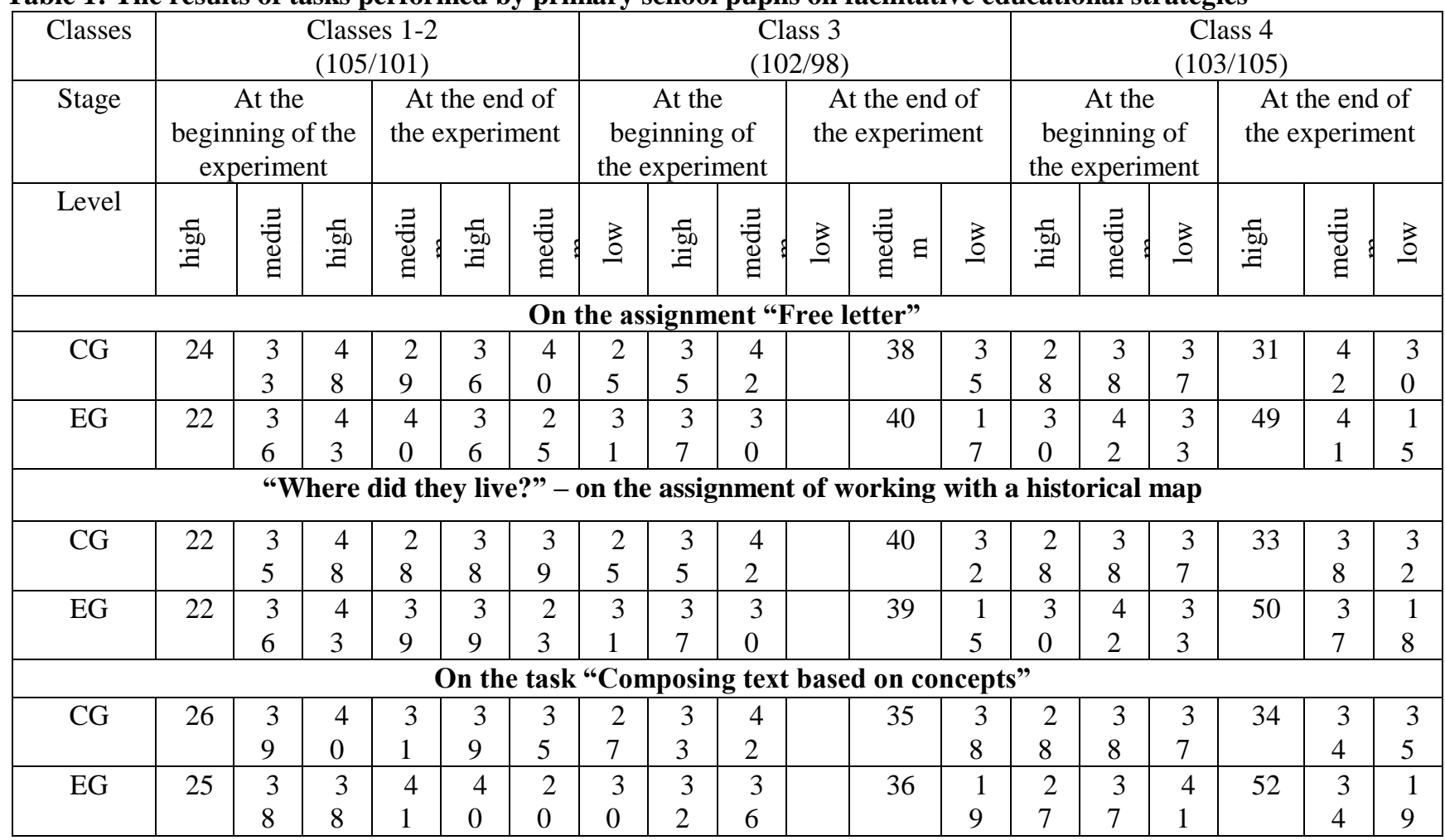

\section{RESULTS}

As a result of the study of changes in the level of development of historical thinking of experimental group pupils, the following were revealed: the stability of the tendency of dynamic growth of development indicators of historical thinking of experimental class pupils was determined; individual differences in the range of relationships are preserved in the development of historical thinking.

\section{CONCLUSIONS.}

Based on the obtained results, a number of conclusions were made: the formation of historical view and consciousness in primary school pupils was achieved, acting as the main elements of the development of historical thinking; the possibilities of such subjects as "Reading" and "The ABC of Ethics", and additional courses as "The ABC of History" and "Journey to the World of History" should be integrated guaranteeing the expected effectiveness of the development of pupils' historical thinking; in the development of primary school pupils' historical thinking, the maintenance of the time-place-fact triad serves to ensure systematic order and consistency; in the development of primary school pupils' historical thinking, a special place should be given to conducting lessons on the introduction, repetition and generalization of the topic, as well as control of knowledge and skills. Also, it is necessary to strengthen the cooperation between "teacher-pupil", "pupil-pupil" and "pupil-historical object" in the study of historical events.

\section{REFERENCES}

1. Abu Nasr Farabi. People of the Ideal City. - Tashkent: Publishing House "Public Legacy" named after A.Kadiri, 1993. - p.222.

2. Abu Rayhan Biruni. Tarayhalar (From the Book of Pearls). - Tashkent: Publishing House "Meros", 1991. - p.47.

3. Alisher Navoi. Selections. Volume 9. - Tashkent: Publishing House "Sharq", 2010. - p.500.

4. Juraev N. Theoretical Bases of Historical Philosophy. - Tashkent: Publishing House "Ma'naviyat", 2008. - p.461.

5. Karimov I.A. Uzbekistan's Own Way of Independence and Development. - Tashkent: Publishing House "Uzbekistan", 1992. - p.78.

6. Karimov I.A. High Spirituality is an Invincible Power. - Tashkent: Publishing House "Ma'naviyat", 2008. - p.76.

7. Mavrulov A. Education of Spiritually Perfect Man. - Tashkent: Publishing House "Uzbekistan", 2008. - p.80.

8. Rakhmonov R., Fayziev F. Historical Consciousness and Historical Memory in the Formation of Youth Worldview. - Tashkent: Publishing House "Uzbekistan", 2009. - p.80.

9. Samiev A.Kh. Historical Consciousness and Development of Human Spiritual World. - Dushanbe: Publishing House "Donish", 1994. p.154.

10. Tulenov J. Philosophic Culture and Spiritual Perfection. - Tashkent: Publishing House "Mehnat", 2000. - p.215.

11. Philosophy: encyclopaedic dictionary (compiler and responsible editor K.Nazarov). - Tashkent: Publishing House "Sharq", 2004. - p.496. 